\title{
An uncommon cause of cholangitis: multiple stenting
}
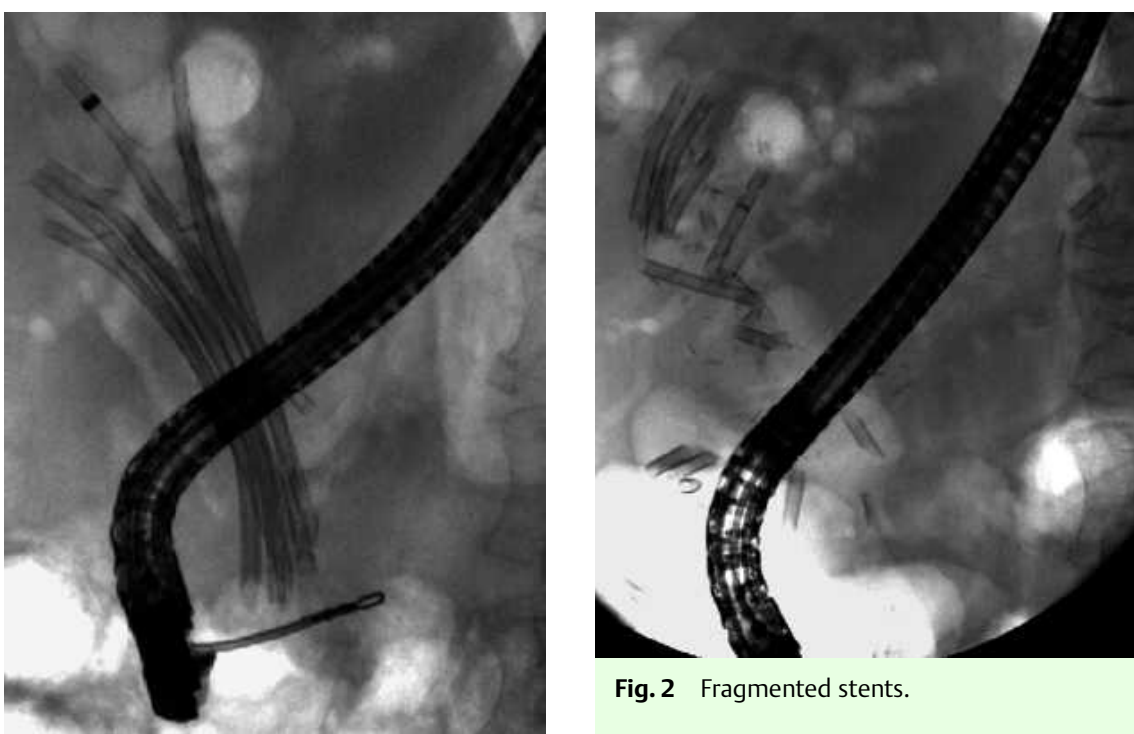

Fig. 2 Fragmented stents.

Fig. 1 Stents in the common bile duct.

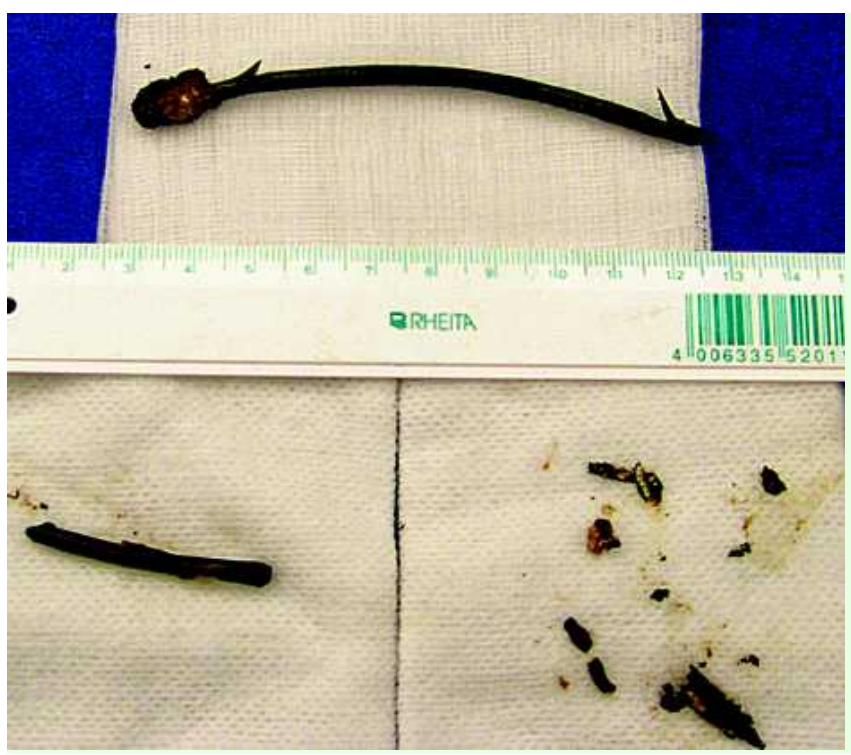

Fig. 3 Extracted stent particles.

Stent treatment of biliary strictures has become a common procedure, and inserting more than one stent (multiple stenting) has been shown to achieve better long-term success rates $[1,2]$. We report on a very uncommon complication of multiple stenting.

A 73-year-old woman was admitted with signs of cholangitis and sepsis. She had a history of a large bile duct stone for which successful treatment in 1999 had only been possible with percutaneously applied laser lithotripsy, despite an ade- quate endoscopic papillotomy (EPT). Due to recurrent stone formation, the percutaneous transhepatic biliary drain was left in situ for 2 years.

As she developed recurrent episodes of cholangitis, with stones and also food particles in the biliary tract, repeated stent therapy had to be started, with finally nine stents during the last session in 2003, intending to block the wideopen biliary ostium. The patient missed her subsequent appointment for the stents to be exchanged.
Four years later, the patient presented at our hospital. Abdominal radiography showed at least six stents in situ, some of which appeared to be broken ( $\bullet$ Fig. 1). Endoscopy showed that all of the stents had become dislocated into a broadly dilated common bile duct. Despite broad access into the bile duct with a large EPT, the stents were difficult to remove, as they had adhered together due to biliary crystallization, with an effect much like that of concrete. When we were able to capture part of a stent, it tended to snap like a matchstick. Each of the stents therefore had to be removed in multiple pieces ( Fig. 2,3). The patient was discharged without any biliary stents.

Stent occlusion is one of the major problems in the treatment of biliary strictures [3]. We feel that patients who have multiple biliary stents more often develop biliary sludge formation. However, the type of complication described here - with diffuse breakage of plastic stents - appears to be very uncommon. The main problem in this patient was probably the large biliary ostium, which repeatedly led to food particles becoming trapped.

Endoscopy_UCTN_Code_CPL_1AK_2AD

\section{P. Born, M. Knieper}

Department of Internal Medicine, Tirschenreuth District Hospital, Tirschenreuth, Germany

\section{References}

1 Draganov P, Hoffman B, Marsh W et al. Longterm outcome in patients with benign biliary strictures treated endoscopically with multiple stents. Gastrointest Endosc 2002; 55: 680-686

2 Costamagna G, Bulajic M, Tringali A et al. Multiple stenting of refractory pancreatic duct strictures in severe chronic pancreatitis: long-term results. Endoscopy 2006; 38: 254-259

3 Donelli G, Guaglianone E, Di Rosa $R$ et al. Plastic biliary stent occlusion: factors involved and possible preventive approaches. Clin Med Res 2007; 5: 53-60

Bibliography

DOI 10.1055/s-2008-1077685

Endoscopy 2008; 40: E250

(c) Georg Thieme Verlag KG Stuttgart · New York . ISSN 0013-726X

\section{Corresponding author}

\section{P. Born, MD}

Department of Internal Medicine

Tirschenreuth District Hospital

St.-Peter-Strasse 31

95643 Tirschenreuth

Germany

Fax: +49-9631-875210

peter.born@krankenhaus-tirschenreuth.de 